\title{
Effect of adipose tissue-derived stem cell injection in a rat model of urethral fibrosis
}

\author{
Premsant Sangkum, MD; Faysal A. Yafi, MD; ${ }^{2}$ Hogyoung Kim, PhD; ${ }^{2}$, Mostafa Bouljihad, PhD; ${ }^{3}$ \\ Manish Ranjan, PhD, ${ }^{2}$ Amrita Datta, PhD; , Sree Harsha Mandava, MD, ${ }^{2}$ Suresh C Sikka, PhD; \\ Asim B. Abdel-Mageed, PhD; ${ }^{2}$ Wayne J.G. Hellstrom, MD²
}

'Division of Urology, Ramathibodi Hospital, Mahidol University, Bangkok, Thailand; 2Department of Urology, Tulane University School of Medicine, New Orleans, LA, United States; ${ }^{3}$ Division of Comparative Pathology, Tulane National Primate Research Center, Covington, LA, United States

Cite as: Can Urol Assoc J 2016;10(5-6):E175-80. http://dx.doi.org/10.5489/cuaj.3435 Published online May 12, 2016.

\section{Abstract}

Introduction: We sought to evaluate the therapeutic effect of adipose tissue-derived stem cells (ADSCs) in a rat model of urethral fibrosis.

Methods: Eighteen (18) male Sprague-Dawley rats (300-350 g) were divided into three groups: (1) sham (saline injection); (2) urethral fibrosis group $(10 \mu \mathrm{g}$ transforming growth factor beta 1 (TGF- $\beta 1)$ injection); and (3) ADSCs group (10 $\mu \mathrm{g}$ TGF- $\beta 1$ injection plus $\left.2 \times 10^{5} \mathrm{ADSCs}\right)$. Rat ADSCs were harvested from rat inguinal fat pads. All study animals were euthanized at two weeks after urethral injection. Following euthanasia, rat urethral tissue was harvested for histologic evaluation. Type I and III collagen levels were quantitated by Western blot analysis.

Results: TGF- $\beta 1$ injection induced significant urethral fibrosis and increased collagen type I and III expression $(\mathrm{p}<0.05)$. Significant decrease in submucosal fibrosis and collagen type I and III expression were noted in the ADSCs group compared with the urethral fibrosis group $(p<0.05)$. TGF- $\beta 1$ induced fibrotic changes were ameliorated by injection of ADSCs.

Conclusions: Local injection of ADSCs in a rat model of urethral fibrosis significantly decreased collagen type I and III. These findings suggest that ADSC injection may prevent scar formation and potentially serve as an adjunct treatment to increase the success rate of primary treatment for urethral stricture disease. Further animal and clinical studies are needed to confirm these results.

\section{Introduction}

Urethral stricture disease is a scarring process of the urethral mucosa and the surrounding spongy tissue of the corpus spongiosum. ${ }^{1}$ The reported estimated incidence of urethral stricture disease in an older veterans population is $0.6 \% .^{2}$ The incidence of urethral stricture diagnoses among Medicare beneficiaries was $1.4 \%$ in 1992 and
$0.9 \%$ in 2001, respectively. ${ }^{3}$ Various modalities are available for the treatment of urethral strictures, including urethral dilatation, direct visual internal urethrotomy (DVIU), and various urethroplasty techniques. The long-term recurrencefree rates after DVIU and urethral dilatation remain quite poor. ${ }^{4}$ Urethroplasty remains the standard of care for urethral strictures, but recurrence rates as high as $15.6 \%$ have been reported following surgery. ${ }^{5}$ Factors predictive of treatment failure are not well-documented. ${ }^{5}$ However, long stricture length $(>4-5 \mathrm{~cm})$, lichen sclerosus, infectious or iatrogenic etiologies, prior urethroplasty, and failed endoscopic therapy are risk factors of urethroplasty failure. ${ }^{6,7}$ Current adjunctive treatments that aim to improve treatment outcomes include injection of mitomycin $\mathrm{c}$ and steroids. ${ }^{8-10}$ Results of these different treatment options remain inconsistent and, as such, none of these modalities have been widely adopted.

Stem cells have the ability to undergo self-renewal and multilineage differentiation, and to form terminally differentiated cells. ${ }^{11}$ Furthermore, a number of animal studies have demonstrated that mesenchymal stem cells have antifibrotic properties that can reduce fibrosis in the lung, kidney, and liver. ${ }^{12-14}$ We sought to evaluate the potential therapeutic benefits of adipose-derived stem cell (ADSCs) therapy in decreasing fibrotic tissue in a rat model of urethral fibrosis.

\section{Methods}

\section{Study design}

These experiments were performed according to the American Guidelines for the Ethical Care of Animals, and were approved by the Tulane University Animal Care and Use committee. A total of 18 adult male Sprague-Dawley rats (300-350 g) were purchased from Harlan Laboratories (Indianapolis, IN, U.S.) and housed in a regulated environment with a 12-hour light and dark cycle in an approved 
experimental laboratory. The animals had free access to food and water. Animals were randomized into three equal groups: (1) sham (saline injection to urethra); (2) urethral fibrosis $(10 \mu \mathrm{g}$ transforming growth factor beta 1 (TGF- $\beta 1$; Aviscera Bioscience, Santa Clara, CA, U.S.) injection); and (3) ADSC (10 $\mu \mathrm{g}$ TGF- $\beta 1$ injection plus $2 \times 10^{5}$ ADSCs). All rats were euthanized at two weeks following normal saline or TGF- $\beta 1$ or TGF- $\beta 1$ plus ADSCs injection. Urethral tissues were harvested and divided into two pieces for further analysis. Histological assessment of urethral tissues was then performed. Type I and III collagen levels were evaluated by Western blot analysis.

\section{Adipose tissue-derived stem cell isolation and culture}

ADSCs were harvested from the inguinal fat tissue of a donor male Sprague-Dawley rat (300-350 g). A lower abdominal skin incision was made and the fat pads around both sides of the inguinal area and spermatic cord were excised. Approximately $1 \mathrm{~g}$ of fresh inguinal fat tissue was washed three times in Dulbecco's phosphate-buffered saline (DPBS) and minced on ice using a sterile blade into three $1 \mathrm{~mm}$ pieces. The minced tissue was suspended in $2 \mathrm{mg} / \mathrm{ml}$ of collagenase type-I (GIBCO, Invitrogen, Carlsbad, CA, U.S.) dissolved in DPBS. The tissue/collagenase suspension was incubated at $37^{\circ} \mathrm{C}$ in a shaking water bath for 2.5 hours. The tissue suspension was then filtered first through a 70 $\mu \mathrm{m}$, followed by $40 \mu \mathrm{m}$, cell strainer to remove the tissue debris. Following this, mature adipocytes were removed by centrifugation (1500 $\mathrm{g}$ for 10 minutes). The formed pellet was then suspended in DPBS and centrifuged again. The resulting stromal vascular fraction pellet was suspended and incubated for two minutes in red blood cell lysis solution (0.15 $\mathrm{M}$ ammonium chloride, $10 \mathrm{mM}$ potassium bicarbonate and $0.1 \mathrm{mM}$ EDTA). ADSCs were washed in $2 \mathrm{ml}$ of $1 \%$ bovine serum albumin (Sigma-Aldrich, St. Louis, MO, U.S.), suspended in Dulbecco's modified eagle's medium (DMEM)/F12 medium (GIBCO, Invitrogen, Carlsbad, CA, U.S.) supplemented with $20 \%$ fetal bovine serum and $1 \%$ antibiotic-antimycotic solution (penicillin G, streptomycin, and amphotericin B; Mediatech, Herndon, VA, U.S.), and maintained at $37^{\circ} \mathrm{C}$ in a cell culture incubator with $5 \% \mathrm{CO}^{2}$.

\section{Flow cytometry}

The rat ADSCs (passage $\leq 3$ ) were evaluated for viability and stained for flow cytometry analysis, as previously described by Donnenberg. ${ }^{15}$ Briefly, $2 \times 10^{5}$ cells were suspended in PBS and were incubated with anti-rat monoclonal antibodies for CD29, CD45, CD90, and CD105. ${ }^{16}$ Also, $2 \times 10^{5}$ rat ADSCs were suspended in $50 \mu \mathrm{L}$ PBS with anti-human CD90 or anti-human CD105 conjugated with either phycoerythrin or fluorescein isothiocyanate (BD Biosciences,
Franklin Lakes, NJ, U.S.) in $50 \mu \mathrm{L}$ of PBS for 30 minutes in the dark at $4{ }^{\circ} \mathrm{C}$. The conjugated cells were washed thrice followed by analysis on a fluorescence-activated cell sorter (FACSCalibur; BD Biosciences, Franklin Lakes, NJ, U.S.). Data acquisition and analysis were performed using Cell Quest software (Becton Dickinson, Franklin Lakes, NJ, U.S.).

\section{Urethral injection procedure}

The urethral injection procedure was performed as previously described. ${ }^{17}$ Briefly, each rat was anesthetized with 100 mg/kg ketamine (NWI Veterinary Supply, Boise, ID, U.S.) and $10 \mathrm{mg} / \mathrm{kg}$ xylazine (Akorn, Decatur, IL, U.S.) intraperitoneally. The rats were placed in the supine position. To facilitate urethral exposure and prevent urethral injury, a lubricated urinary catheter (polyethylene tube, $0.61 \mathrm{~mm}$ in diameter [equal to 1.8 French]) was gently inserted into the urethra. A small penoscrotal incision was created and the rat urethra was meticulously dissected. In the sham group, 0.05 $\mathrm{ml}$ normal saline was injected into the urethra at the 3 and 9 o'clock positions with a 30-gauge needle. The other two groups were injected with $10 \mu \mathrm{g}$ of TGF- $\beta 1(0.05 \mathrm{ml})$ using the same technique in order to induce urethral fibrosis. In the ADSCs group, $2 \times 10^{5}$ ADSCs were injected into the same area immediately after TGF- $\beta 1$ injection. A non-absorbable suture was placed into the corpus cavernosum at the same level of the urethral injection to serve as a landmark for future site identification. The penile skin was approximated with 4-0 interrupted absorbable sutures.

The rats were euthanized at two weeks following the urethral injection. The urethral tissues were harvested and stored for further analysis. The same investigator performed all injections and sacrifice procedures.

\section{Histology}

The rat urethral specimens were harvested and fixed in $10 \%$ buffered neutral formalin and processed using routine histological methods. Haematoxylin and eosin (H\&E) and Masson's trichrome (MT) stained urethral cross sections (4-6 $\mu \mathrm{m}$ thick) were examined using a digital camera (Leica EC3, Leica Microsystems, Heerbrugg, Switzerland) coupled with an optical microscope (Leica Model DM 2500; Leica Microsystems CMS, Weltzar, Germany). The degree of fibrosis was evaluated and described as minimal, mild, moderate, and severe. ${ }^{17}$ All sections were reviewed by the same pathologist, who was blinded to the study design.

\section{Western blot}

Urethral tissue was collected and samples were prepared by homogenizing in radioimmunoprecipitation assay lysis buffer (Santa Cruz Biotechnology, Santa Cruz, CA, U.S.). 
Protein contents were assessed using the Bio-Rad protein assay (Bio-Rad, Hercules, CA, U.S.) according to manufactures protocol. Immunoblot analyses were conducted as previously described..$^{18} 20 \mu \mathrm{g}$ of protein from each lysate was then fractionated by sodium dodecyl sulphate-polyarylamide gel electrophoresis (SDS-PAGE) on a $4-20 \%$ gradient gel and were transferred to a polyvinylidene fluoride membrane. To ensure equal loading and transfer of samples, Ponceau staining was performed and the membrane then probed with antibodies to collagen type I and collagen type III (Abcam, Cambridge, MA, U.S.), and with $\alpha$-tubulin (Cell Signaling, Beverly, MA, U.S.). Appropriate secondary antibodies and horseradish peroxidase based chemiluminescence reagents were used to detect the immune complexes (Pierce, Rockford, IL, U.S.).

\section{Statistical analysis}

Statistical analysis was performed with Prism 5.0 (GraphPad Software, San Diego, CA, U.S.). All data were expressed as means (SD) and the differences between multiple groups were compared by one-way analysis of variance, followed by the Tukey multiple comparisons test $(p<0.05$ was considered statistically significant).

\section{Results}

\section{Characterization of ADSCS}

ADSCs were isolated from the harvested inguinal adipose tissue of a donor rat, and were passaged when $80 \%$ confluence was reached. To ascertain the characteristics of ADSCs, flow cytometric analysis was performed. The ADSCs were strongly positive for mesenchymal stem cell surface markers CD29 (97.48\%), CD90 (98.48\%), and CD105 (96.16\%), whereas they were negative $(0.00 \%)$ for hematopoietic stem cell marker CD45 (Figs. 1A-D). Furthermore, rat ADSCs were also negative for anti-human CD90 $(0.77 \%)$ as well as anti-human CD105 (0.22\%), establishing the specificity of anti-rat antibodies. The last panel revealed the unstained rat ADSCs isotypes (Fig. 1G).

\section{Histology}

Comparative microscopic evaluation of representative H\&E and MT-stained urethral cross-sections revealed normal urethral structure without submucosal fibrosis in the sham group, whereas there was moderate fibrosis with densely packed collagenous stroma involving submucosal tissue in the positive control group. In contrast, there was only mild submucosal urethral fibrosis in the ADSC group (Fig. 2).

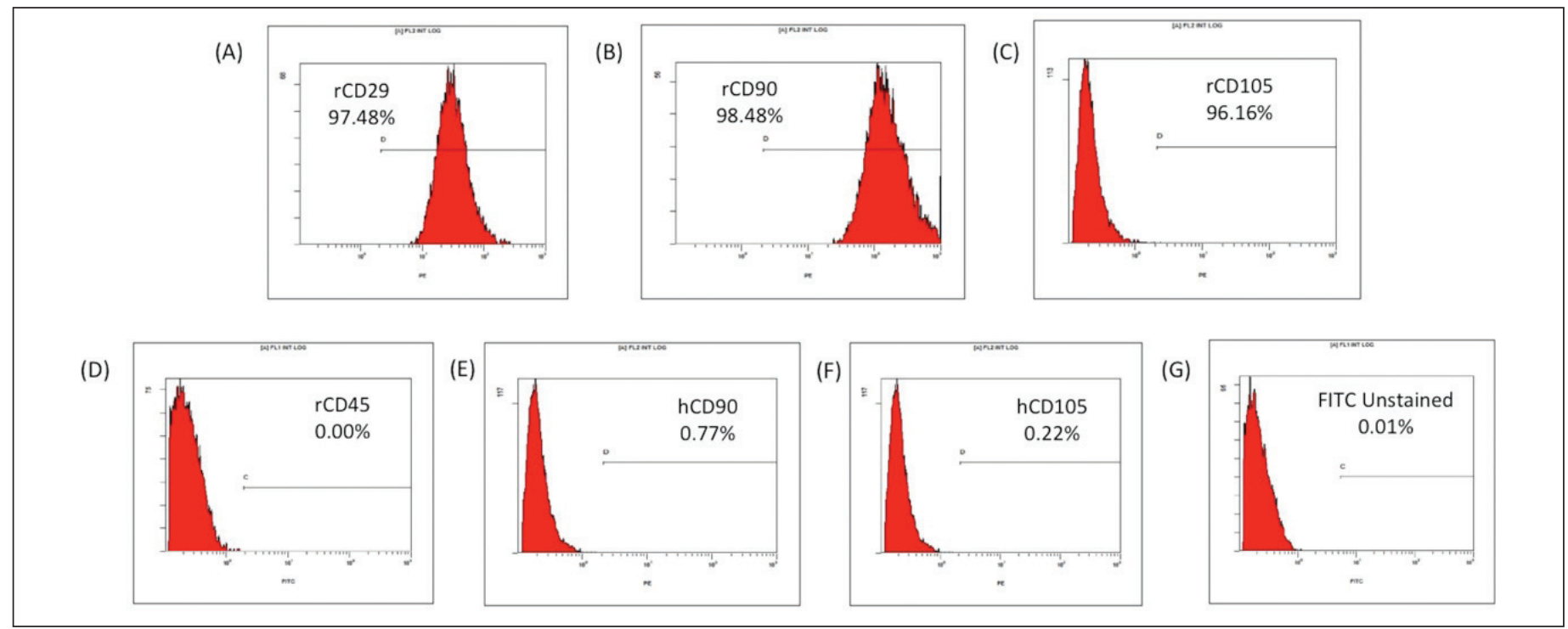

Fig.1. Characterization of adipose tissue-derived stem cells (ADSCs). Flow cytometric analysis of early passage rat ADSCs depicting positive expression for: (A) CD29 (97.48\%); (B) CD90 (98.48\%); (C) CD105 (96.16\%); and (D) negative expression for CD45 (0.00\%). Rat ADSCs were also negative for anti-human: (E) CD90 (0.77\%) and (F) CD105 (0.22\%), further verifying the specificity of the anti-rat antibodies. (G) Unstained ADSC isotypes are shown. 


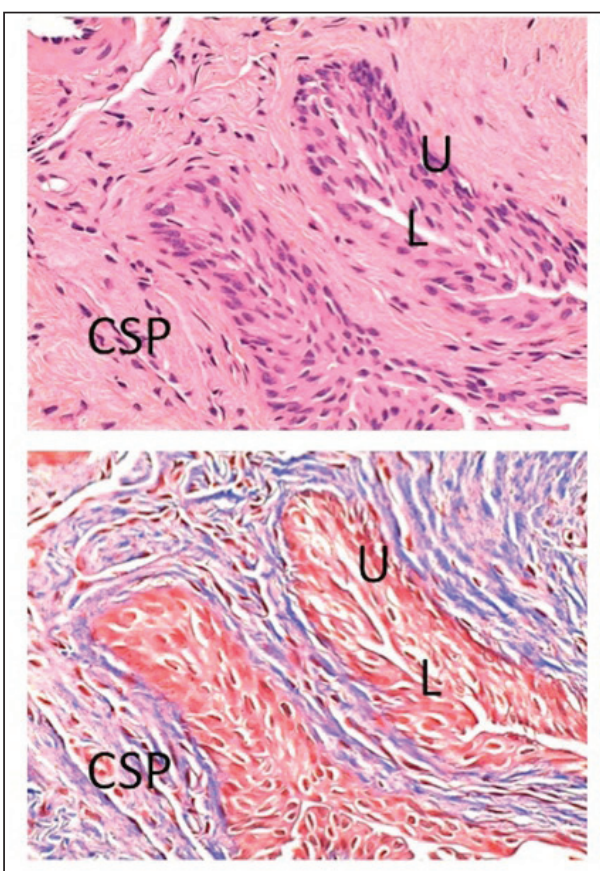

Sham
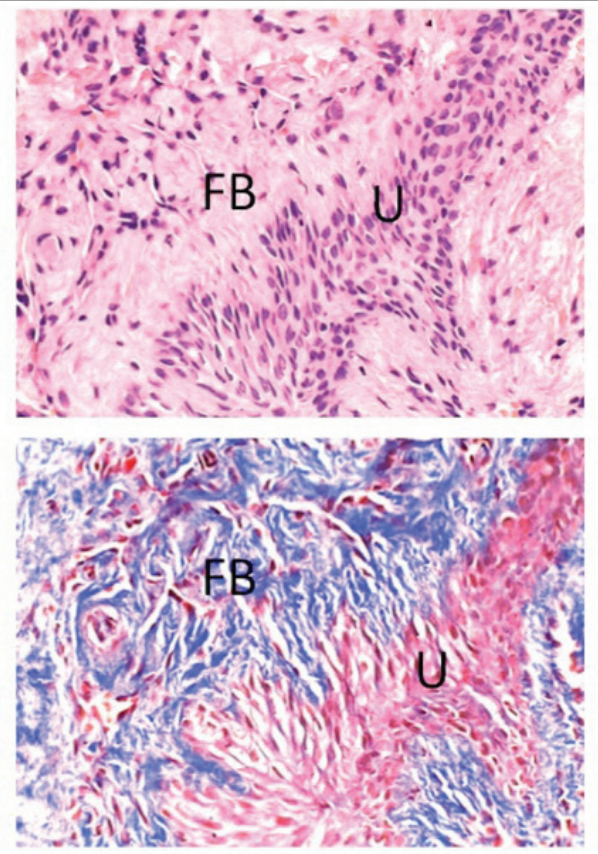

Urethral Fibrosis

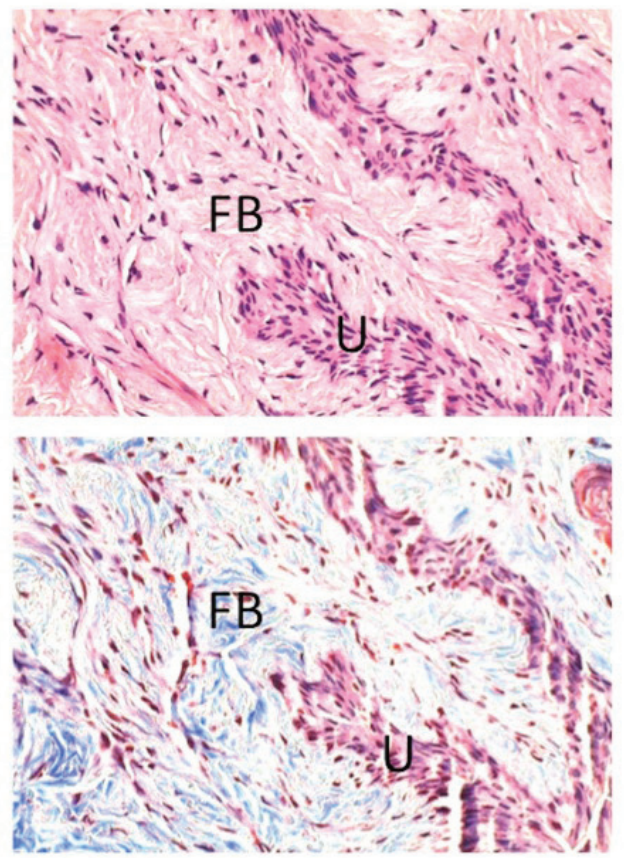

ADSCs

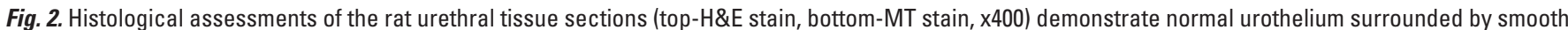

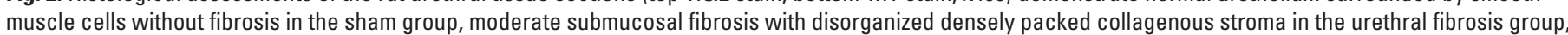
and mild submucosal fibrosis in the ADSC group. Urethral lumen (L), urothelium (U), fibrosis (FB), corpus spongiosum (CSP).

\section{Western blot analysis}

Representative chemiluminescence images of blotted membranes containing protein extract from all three groups are shown in Fig. 3. Western blot analysis demonstrated significantly increased expression of type I and type III collagen levels in the urethral fibrosis group as compared to the sham group. In the ADSC group, there was a significant decrease in collagen type I and III expression $(\mathrm{p}<0.05)$ in comparison with the urethral fibrosis group. Western blot analysis of the expression of collagen corroborated with the histologic findings.

\section{Discussion}

Stem cells are undifferentiated cells that have self-renewal capabilities and are able to differentiate into mature nonregenerative and effector cells. ${ }^{19,20}$ Currently, stem cells can be obtained from embryos, gestational tissue, adult tissue, and using advanced reprograming techniques. Adult stem cells can be isolated from various sources, such as bone marrow, adipose tissue, peripheral blood, connective tissue of dermis, skeletal muscle, etc. ${ }^{18}$ There is an abundance of stem cells in adipose tissue and this is an ideal stem cell source because it can be easily obtained by using a minimally invasive approach. ADSCs are autologous stem cells, which eliminates the risk of rejection and immunosuppres- sion. Furthermore, there are no obvious ethical concerns with using ADSCs, compared to embryonic stem cells. ${ }^{18}$

The study by Liu et al demonstrated that human ADSCs have the capacity to differentiate into urothelium-like cells when co-cultured with urothelial cells. ${ }^{19}$ Furthermore, several animal studies determined that the administration of mesenchymal-derived stem cells significantly reduced fibrosis in the lung, kidney, and liver. ${ }^{12-14}$ There are, however, no reports of stem cell-based therapy in the clinical management of urethral stricture disease. Our study is a proofof-concept study that demonstrates that local injection of ADSCs prevents fibrosis induced by TGF- $\beta 1$ injection.

ADSC injection therapy has been previously studied in a rat model of Peyronie's disease. ${ }^{21,22}$ Local injection of ADSCs into the tunica albuginea decreased Peyronie's-like changes by decreasing the expression of tissue inhibitors of metalloproteinases (TIMPs) and increasing expression of matrix metalloproteinases (MMPs), which resulted in decreased elastosis and fibrosis..$^{21,22}$ Urethral stricture disease and Peyronie's disease have similar fibrotic properties despite involving different anatomic locations. Both conditions are characterized by the formation of fibrous tissue with the same types of collagen. ${ }^{23-26}$ These findings support our observations that local ADSC injection can decrease fibrosis and collagen type I and type III expression in rat urethral tissue. To the best of our knowledge, this is the first animal study 


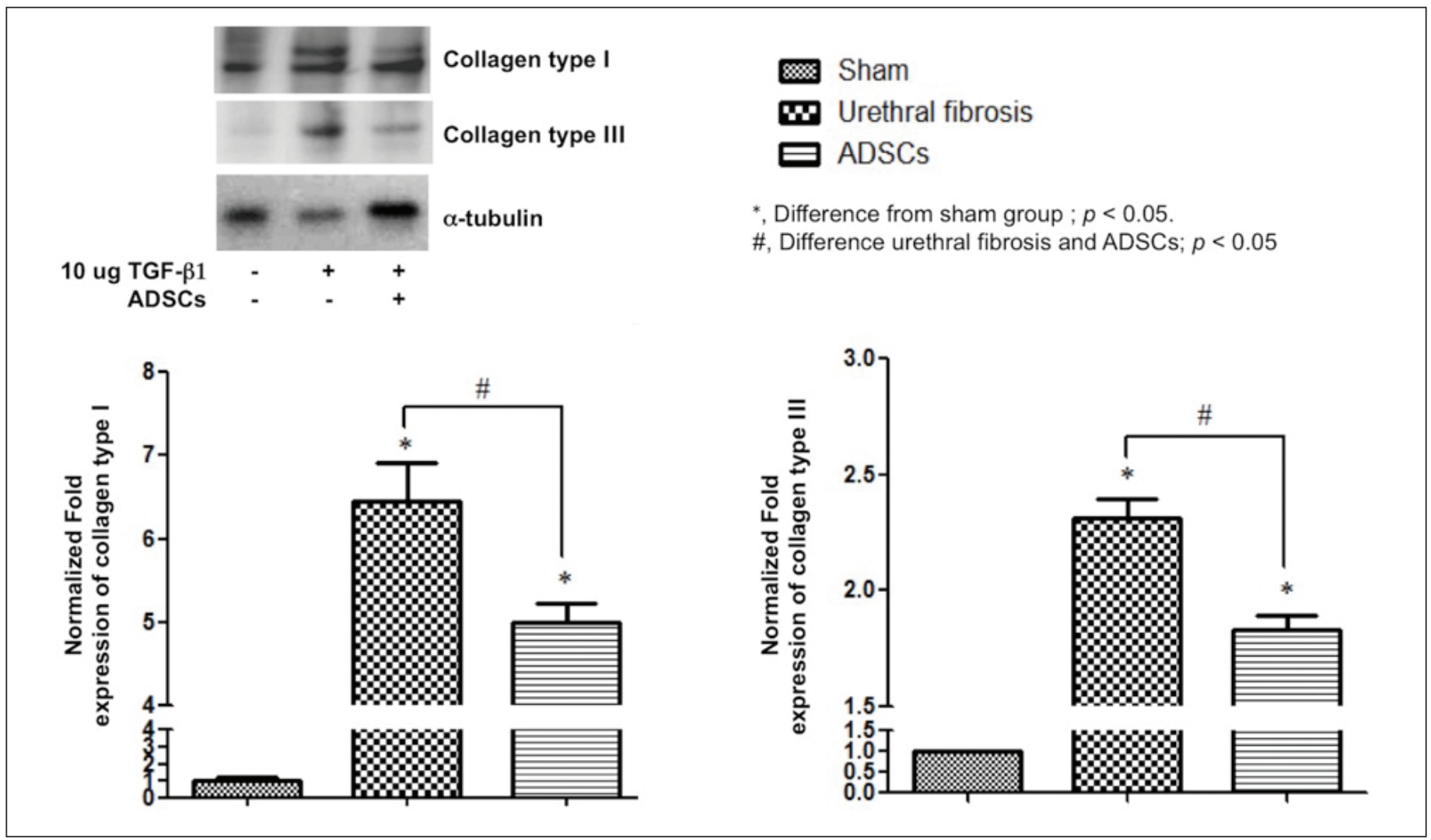

Fig. 3. Representative Western blot demonstrating significantly increased collagen type I and type III in the urethral fibrosis group, whereas there is a significant decrease of collagen type I and type III in the ADSC group. Densitometry demonstrating relative density values of collagen proteins expressed as protein expression relevant to $\alpha$-tubulin control. Results are expressed as mean \pm standard errors ( $p<0.05$ is significant, using GraphPad Prism 5.0).

that has investigated the effect of ADSCs-based injection therapy in a model of urethral fibrosis.

In recent years, stem cell-seeded tissue engineering has been investigated for the surgical treatment of urethral strictures..$^{27,28}$ The concept of the tissue engineering approach is using natural or synthetic matrices (scaffolds) to provide proper position and orientation to promote tissue regeneration. ${ }^{19,29}$ Cell-seeding helps promote the regeneration or reconstruction of new functional tissue. The synthetic matrices or scaffolds are degraded and eventually replaced by an extracellular matrix secreted by the invading cells. ${ }^{19,30}$ ADSCs seeded on a porous silk fibrin scaffold have been successfully used to repair a rabbit urethral defect. Histological examination revealed spontaneous angiogenesis with urethral epithelium and smooth muscle regeneration in the ADSC-seeded group compared to the simple porous silk fibrin scaffold or the control group. ${ }^{28}$

Autologous grafts (buccal, bladder mucosa, lingual, etc.) or flaps have been widely accepted and adopted for use during urethral reconstruction, particularly in the setting of recurrent or complex urethral strictures. Our study demonstrates that ADSC injection therapy significantly reduced tissue fibrosis and collagen expression. Stem cell-based injection therapy to the area of a graft-augmented urethro- plasty would be more practical and easily translatable to clinical practice. We hypothesize that additional injections of autologous ADSCs may improve the outcomes and potentially decrease the recurrence rates after either graft or flap urethroplasty procedures. Further animal and clinical studies are warranted to validate this concept.

One of the limitations of our study is the animal model used. There is no universally accepted animal model for study of urethral stricture disease. The rat model of TGF- $\beta 1$ induced-urethral fibrosis is a novel animal model of urethral fibrosis. Based on our previously published study, we observed a number of TGF- $\beta 1$ receptors in both human and rat urethras, and there was a significant increase in collagen type I and III expression following TGF- $\beta 1$ injection in the same manner as in human urethral stricture specimens. ${ }^{17}$ Furthermore, researchers have demonstrated that halofuginone, which is a specific inhibitor of TGF- $\beta 1$ up-regulation, can prevent urethral fibrosis formation in rat urethra..$^{31,32}$ As such, we postulate this animal model to be suitable for our proof-of-concept study to evaluate the effects of ADSC injections. Our study was focused on the prevention of scar or fibrosis formation. Therapeutic benefits of ADSC injection may not be the same in urethral stricture patients who already have fibrotic scar. However, our findings suggest 
Sangkum et al.

that ADSC injection potentially decreases or prevents scar formation and may potentially serve as an adjunct treatment to increase the success rate of primary treatment for urethral stricture disease patients. Further studies are needed to validate these findings and the potential role of ADSCs injection in urethral stricture patients.

\section{Conclusion}

Local injection of ADSCs significantly attenuates urethral tissue fibrosis, specifically collagen type I and III expression, in a rat model of urethral fibrosis. This data suggests a potential role for ADSC injection therapy in the adjunctive treatment of urethral stricture disease.

Competing interests: Dr. Hellstrom has been an Advisory Board member for Abbvie, Allergan, AMS, Astellas, Coloplast, Endo, Lipocine, Pfizer, and Repros; a Speakers' Bureau member for Endo, Menarini; has received grants/honoraria from Endo/Auxillium; and has participated in clinical trials for Coloplast and NERI. The remaining authors declare no competing financial or personal interests.

This paper has been peer-reviewed.

\section{References}

1. Lumen N, Hoebeke P, Willemsen P, et al. Etiology of urethral stricture disease in the 21st century. J Urol 2009;182:983-7. http://dx.doi.org/10.1016/i.juro.2009.05.023

2. Santucci RA, Joyce GF, Wise M. Male urethral stricture disease. J Urol 2007;177:1667-74. http:// dx.doi.org/10.1016/i.juro.2007.01.041

3. Anger JT, Santucci R, Grossberg AL, et al. The morbidity of urethral stricture disease among male medicare beneficiaries. BMC Urol 2010;10:3. http://dx.doi.org/10.1186/1471-2490-10-3

4. Veeratterapillay R, Pickard RS. Long-term effect of urethral dilatation and internal urethrotomy for urethral strictures. Curr Opin Urol 2012;22:467-73. http://dx.doi.org/10.1097/MOU.0b013e32835621a2

5. Meeks JJ, Erickson BA, Granieri MA, et al. Stricture recurrence after urethroplasty: A systematic review. J Urol 2009;182:1266-70. http://dx.doi.org/10.1016/i.juro.2009.06.027

6. Kinnaird AS, Levine MA, Ambati D, et al. Stricture length and etiology as preoperative independent predictors of recurrence after urethroplasty: A multivariate analysis of 604 urethroplasties. Can Urol Assoc J 2014;8:E296-300. http://dx.doi.org/10.5489/cuaj.1661

7. Breyer BN, McAninch JW, Whitson JM, et al. Multivariate analysis of risk factors for long-term urethroplasty outcome. J Urol 2010;183:613-7. http://dx.doi.org/10.1016/i.juro.2009.10.018

8. Rivers TA, Campbell JT, Greene LF. Treatment of urethral strictures by intralesional infections of steroids, internal urethrotomy and intubation with silastic catheter. J Urol 1974;111:502-3.

9. Mazdak H, Meshki I, Ghassami F. Effect of mitomycin C on anterior urethral stricture recurrence after internal urethrotomy. Eur Urol 2007;51:1089-92; discussion 92. http://dx.doi.org/10.1016/i. eururo.2006.11.038

10. Redshaw JD, Broghammer JA, Smith TG, et al. Intralesional injection of mitomycin C at transurethral incision of bladder neck contracture may offer limited benefit: TURNS study group. J Urol 2015; 193:587-92. http://dx.doi.org/10.1016/i.juro.2014.08.104

11. Bunnell $B A$, Flaat $M$, Gagliardi $C$, et al. Adipose-derived stem cells: Isolation, expansion and differentiation. Methods 2008;45:115-20. http://dx.doi.org/10.1016/i.ymeth.2008.03.006
12. Alfarano $C$, Roubeix $C$, Chaaya R, et al. Intraparenchymal injection of bone marrow mesenchymal stem cells reduces kidney fibrosis after ischemia-reperfusion in cyclosporine-immunosuppressed rats. Cell Transplant 2012;21:2009-19. http://dx.doi.org/10.3727/096368912X640448

13. Moodley Y, Atienza D, Manuelpillai U, et al. Human umbilical cord mesenchymal stem cells reduce fibrosis of bleomycin-induced lung iniury. Am J Pathol 2009;175:303-13. http://dx.doi.org/10.2353/ aipath.2009.080629

14. Zhao W, Li JJ, Cao DY, et al. Intravenous injection of mesenchymal stem cells is effective in treating liver fibrosis. World J Gastroenterol 2012;18:1048-58. http://dx.doi.org/10.3748/wig.v18.i10.1048

15. Donnenberg VS, Donnenberg AD, Zimmerlin L, et al. Localization of CD44 and CD90 positive cells to the invasive front of breast tumors. Cytometry B Clin Cytom 2010;78:287-301. http://dx.doi. org/10.1002/cyto.b.20530

16. Ma L, Yang Y, Sikka SC, et al. Adipose tissue-derived stem cell-seeded small intestinal submucosa for tunica albuginea grafting and reconstruction. Proc Natl Acad Sci USA 2012;109:2090-5. http://dx.doi. org/10.1073/pnas. 1113810109

17. Sangkum $P$, Gokce A, Tan RB, et al. TGF-betal induced urethral fibrosis in a rat model. J Urol 2015;194:820-7. http://dx.doi.org/10.1016/i.juro.2015.02.014

18. Kim H, Naura AS, Errami Y, et al. Cordycepin blocks lung injury-associated inflammation and promotes BRCA1-deficient breast cancer cell killing by effectively inhibiting PARP. Mol Med 2011;17:893-900.

19. Fu Q, Cao YL. Tissue engineering and stem cell application of urethroplasty: From bench to bedside. Urology 2012;79:246-53. http://dx.doi.org/10.1016/j.urology.2011.08.043

20. Blau HM, Brazelton TR, Weimann JM. The evolving concept of a stem cell: Entity or function? Cell 2001;105:829-41. http://dx.doi.org/10.1016/S0092-8674(01)00409-3

21. Gokce A, Abd Elmageed ZY, Lasker GF, et al. Adipose tissue-derived stem cell therapy for prevention and treatment of erectile dysfunction in a rat model of Peyronie's disease. Andrology 2014;2:244-51. http://dx.doi.org/10.1111/i.2047-2927.2013.00181.x

22. Castiglione F, Hedlund $\mathrm{P}$, Van der Aa F, et al. Intratunical injection of human adipose tissue-derived stem cells prevents fibrosis and is associated with improved erectile function in a rat model of Peyronie's disease. Eur Urol 2013;63:551-60. http://dx.doi.org/10.1016/i.eururo.2012.09.034

23. Cavalcanti AG, Costa WS, Baskin LS, et al. A morphometric analysis of bulbar urethral strictures. BJU Int 2007;100:397-402. http://dx.doi.org/10.1111/i.1464-410X.2007.06904.x

24. Da-Silva EA, Sampaio FJ, Dornas MC, et al. Extracellular matrix changes in urethral stricture disease. J Urol 2002;168:805-7. hittp://dx.doi.org/10.1016/S0022-5347(05)64747-7

25. Somers KD, Sismour EN, Wright GL Jr, et al. Isolation and characterization of collagen in Peyronie's disease. J Urol 1989;141:629-31.

26. Luangkhot R, Rutchik $S$, Agarwal V, et al. Collagen alterations in the corpus cavernosum of men with sexual dysfunction. J Urol 1992; 148:467-71.

27. Wu S, Liu Y, Bharadwai S, et al. Human urine-derived stem cells seeded in a modified 3D porous small intestinal submucosa scaffold for urethral tissue engineering. Biomaterials 2011;32:1317-26. http:// dx.doi.org/10.1016/i.biomaterials.2010.10.006

28. Zhang $Y$, Zhou $Y$, Jia $L S$, et al. Repairing urethral defect with adipose-derived mesenchymal stem cells seeded on a porous silk. Jiangsu Med J 2010;36:199-201.

29. Shokeir AA, Harraz AM, El-Din AB. Tissue engineering and stem cells: Basic principles and applications in urology. Int J Urol 2010;17:964-73. http://dx.doi.org/10.1111/j.1442-2042.2010.02643.x

30. Koh CJ, Atala A. Prospects for engineering the urinary tract. Nephron Experimental Nephrology 2004;98:e65-70. http://dx.doi.org/10.1159/000080681

31. Nagler $A$, Gofrit 0 , Ohana $M$, et al. The effect of halofuginone, an inhibitor of collagen type i synthesis, on urethral stricture formation: In vivo and in vitro study in a rat model. J Urol 2000;164:1776-80. http://dx.doi.org/10.1016/S0022-5347(05)67105-4

32. Krane LS, Gorbachinsky I, Sirintrapun J, et al. Halofuginone-coated urethral catheters prevent periurethral spongiofibrosis in a rat model of urethral injury. J Endourol 2011;25:107-12. http://dx.doi. org/10.1089/end.2010.0514

Correspondence: Dr. Wayne Hellstrom, Department of Urology, Tulane University School of Medicine, New Orleans, LA, United States; whellst@tulane.edu 